\title{
Aportes Saidianos para um Direito (Des)Colonial: sobre iconologias de revoluções e odaliscas
}

\author{
Saidian Inputs to a (De)Colonial Law: on revolutions \\ and odalisques iconologies
}

\author{
Antonio Carlos Wolkmer \\ Universidade La Salle (UNILASALLE-RS) - Canoas, RS, Brasil.
}

Ana Clara Correa Henning Universidade Federal de Pelotas (UFPel) - Pelotas, RS, Brasil.

\begin{abstract}
Resumo: Neste trabalho foram apresentados debates acerca da classificação eurocêntrica entre o "eu" ocidental e o "outro" oriental, a partir das teorizações de Edward Said sobre orientalismo e relações entre colonialismo e cultura. Serão analisadas, para isso, obras de pintores europeus do século XIX por meio do método iconológico, comparando-as e ressaltando a marginalidade de algumas delas e a centralidade de outras. Compreende-se que tais representações podem ser encontradas, igualmente, no direito ocidental como discurso de poder colonial, exercido tanto na metrópole quanto na periferia, que perdura em nossos dias e suscita resistências e oposições.
\end{abstract}

Palavras-Chave: Edward Said. Arte Europeia do século XIX. Método Iconológico. Direito Colonial. Direito Descolonial.
Abstract: Applying the ideas of Edward Said about orientalism and about the relationship between colonialism and culture, we discuss the eurocentric opposition between the Western "I" and the Oriental "other". Works by 19th century European painters are analyzed with the iconological method and compared, to underline the marginality of some images and the centrality of others. We show that similar representations are found in the Western law, as a discourse of the colonial power exerted in the metropolis and also in the periphery, a discourse that still lives today and still finds resistance and opposition.

Keywords: Edward Said. European art of the Nineteenth Century. Iconological Method. Colonial Law. Decolonial Law.

Recebido em: 30/08/2016

Revisado em: 22/10/2017

Aprovado em: 17/11/2017 


\section{Introdução}

Ler essas grandes obras do período imperial em retrospecto e numa heterofonia com outras histórias e tradições em contraponto, lê-las à luz da descolonização, não significa minimizar sua grande força estética nem tratá-las de modo reducionista como propaganda imperialista. Todavia, erro muito mais grave é lê-las desvinculadas de suas ligações com os fatos políticos que lhes deram espaço e forma. (SAID, 2011, p. 260)

Os contemporâneos debates sobre o descolonialismo alcançam os mais variados campos do conhecimento; este é um tema transdisciplinar ao ponto de tornar-se extremamente difícil desenvolver estudos sobre ele restritos a apenas uma área específica. Portanto, neste texto perpassam discussões sobre metodologia, arte, história, relações de poder, colonialismo, dentre tantos outros assuntos que se entende indispensáveis para compreender o alcance e a força do direito aplicado em territórios não ocidentais, conquistados por países europeus, especialmente França e Inglaterra.

A delimitação do nosso tema possui duas dimensões: sua fundamentação teórica e seu limite temporal. Edward Said foi um dos grandes precursores dos estudos descoloniais. Suas obras possuem força e profundidade, ainda que não sejam isentas de críticas e complementações. Utilizou-se os aportes teóricos de dois de seus livros: Orientalismo e Cultura e Imperialismo. Em ambos os textos, perpassa o debate acerca do colonialismo europeu sobre o Oriente, das representações que aquele faz a respeito deste e de que maneira artefatos culturais - como as pinturas aqui trazidas e o direito então utilizado - criam um imaginário social por meio de narrativas que possuem uma realidade material, conforme se verá. Coadjuvaou-se suas falas com autores de diversas áreas, a fim de complementar o pensamento saidiano, comprovar certas afirmações, ressaltar resistências sociais e individuais às tramas de poder e desenvolver alguns conceitos pertinentes ao tema escolhido.

Delimita-se nossa pesquisa, igualmente, traçando um limite temporal, pois focaliza-se as relações estabelecidas entre metrópole e periferia 
no decorrer do século XIX sob a representação de dois pintores franceses, Delacroix e Ingres. Interessa-nos a conexão entre imagens e direito, as possibilidades de compreender melhor determinada cultura jurídica por meio, especialmente, de análises de pinturas e de algumas características de seus autores. Visando esse objetivo, dividiu-se o texto em quatro partes. Inicialmente aponta-se algumas intersecções entre o ambiente cultural, os sistemas jurídicos e a formação de identidades, expondo, também, o método iconológico utilizado na análise das imagens escolhidas.

A segunda parte é reservada à apreciação de duas obras, A Liberdade Guiando o Povo (DELACROIX, 1830) e Fanáticos de Tanger (DELACROIX, 1837), ressaltando suas conexões teóricas com diversos campos de conhecimento, especialmente condizentes a aspectos jurídico-culturais do Oitocentos. O mesmo método analítico é utilizado na seção seguinte, em relação à Condessa de Haussonville (INGRES, 1845) e A Grande Odalisca (INGRES, 1814). Para melhor acompanhamento do desenvolver de nosso raciocínio, recomenda-se a visualização dessas pinturas, cujos endereços eletrônicos encontram-se nas referências. Ao fim, a partir do que será debatido no decorrer do texto, desenvolve-se considerações acerca do direito colonial e de possibilidades de sua descolonização.

\section{Conexões entre Cultura, Direito e Identidades: iconologia como ferramenta de trabalho empírico}

\subsection{Direito como Artefato Cultural, Método Documentário e Iconologia}

O mundo de culturas no qual se vive é, sob diversas formas, extremamente imagético. Os meios pictóricos possuem uma força imediata de convencimento dificilmente encontrada em outras formas de comunicação, sendo utilizados desde em peças publicitárias até regras de legislação, de materiais didáticos à construção e queda de ícones sociais. Parte-se da compreensão de que o entorno cultural é construído - e, por sua vez, constrói - mentalidades e percepções compartilhadas em determinado tempo e lugar. 
A mútua influência entre a narrativa cultural (seja pela pintura, pelo romance ou outra forma de manifestação artística) e as dimensões históricas, políticas e econômicas da sociedade onde aquelas obras são produzidas ou possuem alcance é um dos objetos de estudo de Edward W. Said (2011), norte-americano de origem palestina. Ele é considerado um dos precursores dos estudos pós-coloniais (CASTRO-GÓMEZ, 2005, p. 20) com seu livro Orientalismo (SAID, 2012), publicado em 1978, em que discorre sobre a constituição (imaginária e material) do Oriente por meio do discurso eurocêntrico de superioridade sobre não europeus. Esse discurso, para Said, engloba narrativas políticas, econômicas, morais, jurídicas - enfim, tem como substrato produções culturais tanto ocidentais quanto aquelas realizadas nas antigas colônias europeias.

Observa-se que também o direito é um artefato cultural. Construído por homens e mulheres, descreve comportamentos, representa alegados consensos, procura organizar a sociedade sob certa hierarquia de ações e, por vezes, punições. Nesse sentido, ele também cria imagens a servirem de modelos de conduta social:

O direito não chega até a solicitar as cores para tornar-se mais imperativo? Preta é a roupa dos magistrados e dos auxiliares de justiça, escura as forças da polícia. Cores que fazem eco ao preto do uniforme do árbitro e da batina do padre. Todas essas personagens estão aí para lembrar a regra e, se preciso, forçar sua observação. O fúnebre não está longe. Mas também o vermelho, a cor de que gosta o poder (pensemos nos púrpuras imperial e cardinalício, nos diversos tapetes vermelhos): os magistrados das altas jurisdições se revestem dele; ele colore a capa da maior parte dos códigos franceses; deu seu nome aos sinais de trânsito que prescrevem parar [...] O direito se impõe até à nossa retina. (ROULAND, 2008, p. 6-7, grifos nossos)

As dimensões indicadas por Said e Rouland são válidas para o estudo da cultura visual em sociedades (ainda que não inteiramente) letradas, nas quais não raro a imagem substitui a escrita. É interessante observar a diversidade de imagens e cores que, conjugadas, traduzem uma narrativa: fotografias em mídias impressas e eletrônicas, sinais de trânsito, dispo- 
sição de um tribunal do júri, obras expostas em um museu de artes plásticas. Muitas delas, acessíveis a qualquer pessoa; outras, direcionadas a um grupo de conhecedores, ainda que tecnicamente disponíveis ao conhecimento popular. Todas, de uma maneira ou de outra, relacionadas com perspectivas e visões de mundo próprias das sociedades que lhes deram origem.

Ainda que os empreendimentos coloniais tenham origem mais antiga do que o século XIX (MIGNOLO, 2008, p. 7), aqui propõe-se compreender aspectos do direito colonial através de algumas percepções eurocêntricas naturalizadas que influenciaram pinturas oitocentistas. Para isso, realizou-se uma pesquisa empírica, utilizando o método de análise documentária (BOHNSACK, 2007), considerando as imagens como fontes diretas e documentais (KNAUSS, 2006, p. 100).

A diferenciação entre pré-iconografia, iconografia e iconologia, segundo Ralf Bohnsack (2007, p. 290-292), reside nas perguntas feitas pelo pesquisador no momento da análise imagética. De início, indaga-se sobre o que é representado: pessoas, fatos históricos, paisagens, acontecimentos. Tanto a pré-iconografia quanto a iconografia são ateóricas, regidas por percepções imediatas e descritivas. Na primeira, a descrição da obra alcança sua composição, a incidência de luz e sombra, as tonalidades das cores ali utilizadas. Na segunda, sua intencionalidade, ou seja, o que a imagem quer nos representar.

O momento seguinte será o das indagações iconológicas, perguntando-se sobre a forma pela qual tais fatos foram produzidos tanto pelo autor da imagem quanto pelos personagens - se os houver. Essa etapa demanda aprofundamento teórico e contextualização histórica do momento ali representado e das ações das pessoas retratadas. Da mesma forma, se faz necessário o conhecimento das influências artísticas do autor da obra sob estudo, a escola a que está filiado e, muitas vezes, aspectos de sua história de vida. 


\subsection{Produção de Representações e de Identidades: proposta de roteiro de pesquisa empírica}

A fim de operacionalizar nossa investigação, associou-se o método documentário aos estudos de Martine Joly (2012). O roteiro de investigação elaborado por ela traz praticidade ao estudo, sem descuidar das complexas nuances indispensáveis para a compreensão do significado da imagem. É preciso lembrar-se de que esta representa, evoca, substitui a coisa retratada. Produz sentidos e significações, inseridos no momento histórico em que a obra foi elaborada (JOLY, 2012, p. 16-17). Desse modo:

Os campos de estudo, tanto quanto as obras até do artista mais excêntrico, são restritos e influenciados pela sociedade, por tradições culturais, pela circunstância mundana e por influências estabilizadoras como as escolas, as bibliotecas e os governos; além disso, [...] tanto os escritos eruditos como os imaginativos nunca são livres, mas limitados nas suas imagens, pressuposições e intenções; e [...] são menos objetivamente verdadeiros do que muitas vezes gostaríamos de pensar. (SAID, 2012, p. 274)

Joly (2012, p. 63-113) elabora suas análises pictóricas em quatro etapas. Inicialmente, contextualiza a escola artística em que o pintor está filiado, identificando diferenças com outras escolas; em seguida, descreve a imagem, ressaltando as escolhas por formas, cores, a maneira pela qual os elementos estão dispostos no quadro, iluminação e ângulo. Na terceira etapa, observa os significados icônicos, incluindo as representações das pessoas porventura retratadas e as qualidades que lhes são atribuídas; por fim, identifica as mensagens linguísticas da obra, seu título e possíveis legendas, tudo o que possa amenizar os sentidos polissêmicos, típicos das imagens.

Conjugando o método de Bohnsack (2007) com o de Joly (2012), elaborou-se um roteiro de estudo cujos passos expõe-se de maneira sintética a seguir: a) contextualização da escola artística e informações biográficas do pintor; b) dimensões pré-iconográfica e iconográfica, com a descrição da imagem; c) etapa iconológica, observando-se os significados 
e representações da narrativa ali exposta, considerando-se, inclusive, os títulos das obras.

Os métodos de análise de imagens desses autores são valiosas ferramentas de pesquisa empírica em fontes diretas/documentais. Para os fins deste texto, eles são úteis para conectar narrativas visuais e sistemas jurídicos do Oitocentos, tomando ambos - direito e pintura - como estratégias de poder e de convencimento não apenas estético, mas social (KNAUSS, 2006, p. 112). Dessa forma, é possível perceber as obras de arte aqui estudadas como produtos de sua época. Mas, igualmente, como produtoras de gostos estéticos, percepções de mundo, hierarquia de valores em grupos de pessoas que possuíam acesso a esses tipos de manifestações culturais (como governantes, burguesia europeia e intelectuais) através de exposições sistemáticas em salões e galerias de arte.

Tais representações ultrapassaram o Ocidente, alcançando outras dimensões geográficas e dando suporte a um imaginário cultural europeu que abria uma fissura entre a metrópole e as colônias. É importante recordar que o empreendimento colonial virá a conhecer expansões sem precedentes especialmente no final do século XIX (MERLE, 2004, p. 729). Suas instituições, como o ensino e a ciência, seguiam essa trilha, disciplinando e classificando pessoas e conhecimentos. Assim, a pedagogia ensinava, por meio da literatura inglesa, a superioridade europeia - tanto em escolas metropolitanas quanto coloniais; a etnografia aprofundava o abismo cultural produzindo e expondo imagens que remetiam a barbarismos e primitivismos nativos (SAID, 2011, p. 173).

Ainda assim, a experiência colonial é construída por incongruências, ressentimentos, resistências, mas também compatibilidades, colaboração e convencimento. Experiências mútuas, dependências e diálogos. Nem a metrópole, nem a colônia saíram ilesas dessas relações: suas identidades foram forjadas por processos de exclusão e, por causa disso, inclusão. Em estudo sobre a obra de Edward Said, Juan Ignacio Castien Maestro (2013, p. 13-14) afirma:

O conteúdo de cada identidade, própria ou alheia, integrado pelas diferentes características que se atribuem a cada qual pelo fato de 
possuir determinada identidade, não é algo que se possa entender de maneira isolada. Ao contrário, só pode ser realmente compreendido quando se compara com o conteúdo das outras identidades às quais se contrapõe. [...] $\mathrm{O}$ outro não é para nós um mero objeto de contemplação; também é objeto de nossas ações e nós das suas, ainda que isso possa dar-se de um modo um tanto indireto ${ }^{1}$.

Daí que as obras coloniais - artísticas ou não - criavam conhecimento, proporcionavam contemplação e estudo, inúmeras vezes construíam a realidade que descreviam, agindo sobre europeus e não europeus. Esse substrato social é compartilhado por qualquer artefato cultural produzido na mesma época - incluindo o sistema jurídico ali vigente. Pois o direito também contribuiu nessa empreitada de transformar o Oriente em uma província da erudição europeia, domesticando-o, reunindo e traduzindo sua legislação, classificando costumes e comparando-os aos europeus (SAID, 2012, p. 120-121).

Essas obras, afinal, não são neutras, mas refletem prazeres e desprazeres, ódios e paixões. Dessa forma, ao analisar as pinturas aqui descritas, o objetivo é ressaltar o contraste entre a marginalidade de certas representações, a centralidade de outras e as inúmeras estratégias que daí advieram. Em uma perspectiva saidiana, não nos cabe julgar as evidentes qualidades das suas técnicas artísticas, mas realizar uma leitura que permita o entrecruzamento de resistências e colonialismos, uma vez que representar é, de alguma forma, também participar da batalha (SAID, 2011, p. 484 e 139).

\footnotetext{
${ }^{1}$ Do original: El contenido de cada identidad, propia y ajena, integrado por los distintos rasgos que se le atribuyen a cada cual por el hecho de poseer esa determinada identidad, no es algo que pueda entenderse de manera aislada. Por el contrario, sólo puede ser realmente comprendido cuando se lo coteja con el contenido de las otras identidades a las que se contrapone. [...] El otro no es para nosotros un mero objeto de contemplación; también es objeto de nuestras acciones, y nosotros de las suyas, aunque ello pueda darse de un modo un tanto indirecto. Esta e as demais traduções foram realizadas pelos autores.
} 


\section{Revolução Ocidental e Turba Oriental: entrecruzamentos de representações da Europa e de seus "outros"}

\subsection{Revolução Legitimada: A Liberdade Guiando o Povo}

Pode-se pensar no tema de estudo aqui proposto, nas representações de certas percepções europeias por meio da pintura oitocentista. Aquele era um mundo em expansão: tão importante foi o período entre $1815 \mathrm{e}$ 1914 para o colonialismo europeu, que Marcel Merle (2004, p. 729) o denomina de "a hora da verdade" - a Europa detinha, já em 1815, 35\% da superfície terrestre, incluindo suas colônias além-mar; o percentual sobre para impressionantes 85\% em 1914 (SAID, 2012, p. 74).

À expansão territorial somam-se, entre outros fatores, o avanço tecnológico e das comunicações, o aumento significativo de produção e de bens de consumo, o crescimento da população em países europeus (HOBSBAWM, 2010, p. 272-273). Muito pouco disso, entretanto, revertia em benefício dos povos e territórios colonizados, diante de uma disciplina espoliadora, da impossibilidade de autogoverno e do aprofundamento do abismo social entre europeus residentes e nativos.

A Inglaterra, por exemplo, levou algumas vantagens às suas colônias (especialmente no que se refere à administração e ao modo civilizatório) e respeitou, sempre que possível, as religiões locais. Mesmo assim, apesar dos esforços ingleses, "[...] as estatísticas coloniais revelam que a malária, as doenças respiratórias, a tuberculose e a disenteria estão na origem de aproximadamente $90 \%$ da forte mortalidade indiana de 1872 a 1921 [...]"; soma-se a grave crise de fome que assolava a Índia, iniciada em 1876 e que durou até 1920 (FOURCADE, 2004, p. 355-356). A realidade local era tão diferente da metrópole, que mesmo que a Inglaterra lançasse mão de todo o avanço da medicina (o que não era muito provável, em vista da relação colonial que existia) tornava-se difícil combater tais doenças. É de se observar que, não coincidentemente, o período em que a população local foi atingida pela fome e pelas doenças referidas foi, praticamente, o mesmo. 
Paralelamente a isso, o comércio de açúcar, escravos, algodão, ópio e metais preciosos por parte das metrópoles era intenso. Alia-se a tais fatos o comprometimento da circulação de bens culturais e pessoas, criando uma atmosfera propicia à aceitação da ideia de subjugação de raças consideradas biológica e racionalmente inferiores e atrasadas pelas nações ocidentais, no que Ramón Grosfogel denomina de "racismo epistêmico ou islamofobia" (GROSFOGEL, 2011, p. 343). Isso dava certa coerência em um conjunto de experiências, de uma maneira ou de outra, compartilhados:

Um jovem inglês enviado para a Índia, para fazer parte do serviço público "pactuado", pertenceria a uma classe cujo domínio nacional sobre qualquer indiano, por mais rico e aristocrático que fosse, era absoluto. Ele conheceria as mesmas histórias, teria lido os mesmos livros, frequentado as mesmas aulas, participado dos mesmos clubes de todos os outros jovens funcionários coloniais. (SAID, 2011, p. 246)

É por isso que Said entende que o Orientalismo é uma maneira de compreender o Oriente: um lugar não apenas adjacente à Europa, mas também território de colônias europeias (especialmente francesas e britânicas), um "Outro", seu rival cultural. Sua construção intelectual integra a cultura material da Europa: um discurso configurado em instituições, vocabulário, erudição, imagens e burocracias coloniais (SAID, 2012, p. 27-28).

As manifestações artísticas criavam um espaço autorizado de discurso, conectando a vida na metrópole com o cotidiano periférico, por meio de representações de domínio, controle e todo um conjunto de significados do que é conveniente ou não para aqueles que habitavam nos dois lados da linha divisora. Com o passar do tempo, as sociedades acabaram por se diferenciar a tal ponto, que o orientalismo torna-se fonte de identidade tanto para os ocidentais quanto para seus "outros". Daí a disseminação na Europa de "[...] novos estilos artísticos, inclusive a fotografia de viagem, a pintura, poesia, literatura e música exóticas e orientalistas, além da escultura monumental e do jornalismo." (SAID, 2011, p. 104 e 185). 
As condições de possibilidade estavam dadas. O entorno cultural contribuiu, de maneira muito forte, para que isso ocorresse. Não se sugere que tais manifestações artísticas causaram o imperialismo, nem que todas as marcas existentes nas ex-colônias estão ali devido ao domínio europeu. Mas sim que a cultura europeia validou-se, frequentemente, a si mesma, traçando linhas divisórias entre ela e outros povos, reafirmando seu domínio nesses territórios distantes (SAID, 2011, p. 144-145).

A disciplina de corpos que essa mentalidade proporcionou reflete-se, por exemplo, nas obras de Eugène Delacroix e Jean-Auguste Ingres, pintores contemporâneos na França do século XIX. Ainda que filiados a escolas artísticas rivais, alguns de seus trabalhos aqui analisados são exemplos do discurso orientalista do qual se vem tratando. Foram escolhidas quatro de suas pinturas para análise neste texto, de acordo com o roteiro anteriormente elaborado: A Liberdade Guiando o Povo (DELACROIX, 1830), Fanáticos de Tanger (DELACROIX, 1837), Condessa de Haussonville (INGRES, 1845) e A Grande Odalisca (INGRES, 1814).

Inicia-se, assim, com o autor de La Liberté Guidant le Peuple, cujas obras foram inspiradas por temas dramáticos, ações por vezes heroicas e violentas. Nascido em 1798 e falecido em 1863, Ferdinand Victor Eugène Delacroix foi um dos mais importantes expoentes da França oitocentista, cuja administração lhe encomendou as pinturas dos tetos do Palácio Luxemburgo e do Palácio Bourbon. Ele simboliza a escola romântica em seu país, caracterizada pela valorização das cores, do movimento, do contraste entre o claro e o escuro, tendo por tema o sujeito, o indivíduo herói, sombrio ou mesmo devasso, tudo a fim de alcançar um resultado menos racional e o mais emotivo e dramático possível (COSTA, GOMES, MELO, 2014, p. 477).

O combate ao racionalismo neoclássico e o apelo a causas nacionalistas fazia com que os artistas românticos fossem "[...] inspirados e envolvidos de forma direta pelos assuntos públicos [...]", sendo "[...] frequentes as temáticas de cunho social, que remetem a acontecimentos nacionais e contemporâneos na vida dos artistas" (VIEIRA, 2009, p. 10). Era um momento histórico convulsionado pela dupla revolução - francesa e inglesa (HOBSBAWN, 2009, passim). A Liberdade Guiando o Povo 
(DELACROIX, 1830) popularizou-se como um símbolo da Revolução Francesa, ainda que não faça referência a ela, mas a um levante popular francês em 1830. Mais tarde, essa obra se tornaria ícone para o nacionalismo na França (BELL, 2008, p. 318).

$\mathrm{Na}$ obra, Delacroix retrata diversas pessoas em meio à luta nas ruas de Paris. Emoldurada pela fumaça da batalha, uma figura feminina de vestes brancas e fluidas ocupa o centro do quadro, especialmente iluminada em contraste com os demais personagens. Carregando, com uma das mãos, a bandeira republicana vermelha, branca e azul, e com a outra, uma baioneta, ela segue em frente, pisando sobre corpos de combatentes caídos durante a batalha, liderando um grupo de revolucionários. As pessoas ao seu redor vestem-se com roupas de todos os tipos: vestimentas comuns de operários, paletós, cartola, camisas maltrapilhas. Todos portam armas, sejam pistolas, carabinas ou espadas. Segundo um crítico de arte:

A pintura inteligentemente combina corajoso registro contemporâneo com alegoria de uma forma monumental. Lugar e tempo estão claros: Notre Dame é visível ao longe e pessoas estão trajadas de acordo com sua classe, com um garoto mal vestido a direita simbolizando o poder das pessoas comuns ${ }^{2}$. (FARTHING, 2011, p. 395)

O título da obra contribui para sua compreensão. Evidencia certos elementos em detrimento de outros. Aqui, a palavra liberdade é fundamental, inclusive o seu conceito para a escola à qual se filiava Delacroix. O romantismo usualmente associava liberdade com independência nacional. Dessa forma:

É aqui que se insere a Liberdade de Delacroix. Ela guia o povo, ela não o comanda, não o ordena, não tira dele a percepção de que ele é agente em um mundo material e em que as entidades abstratas precisam se personificar - tornar-se iguais - para agirem igualmente. (COSTA; GOMES; MELO, 2014, p. 481, grifos no original).

\footnotetext{
${ }^{2}$ Do original: The picture cleverly combines gritty contemporary reportage with allegory in a monumental way. Place and time are clear: Notre Dame is visible in the distance and people are dressed according to their class, with the scruffy boy on the right symbolizing the power of ordinary people.
} 
A personificação iluminada da Liberdade à frente de franceses no campo de batalha urbano é, dessa forma, emblemática. Aquelas pessoas lutavam por sua autodeterminação, pela possibilidade de se organizarem politicamente, libertos de um jugo que não lhes convinha. Carregavam consigo instrumentos que lhes permitiriam a conquista desse objetivo: armas e bandeira, força e nação. A moderna ideia de estado aí se legitima e com ela traz conceitos jurídicos de soberania nacional e liberdade individual, protetores dos cidadãos contra avanços externos ao seu país e lesões à sua dimensão privada: identidade, privacidade e patrimônio.

\subsection{Turba desautorizada: Fanáticos de Tanger}

A narrativa elaborada em A Liberdade Guiando o Povo nos permite pensar que os revolucionários franceses e seus sucessores realizariam mudanças radicais nos destinos de suas colônias. O que houve foram demonstrações do poderio colonial: a Louisiana, por exemplo, foi vendida aos Estados Unidos por Napoleão, em 1803 - seu preço, 15 milhões de dólares. Enfim, “[...] o que pesam algumas 'ilhas de açúcar' diante da fascinação do braseiro revolucionário e da glória do império?” (MERLE, 2004, p. 728).

Dentro desse discurso, o monismo jurídico ocupa lugar de destaque, podendo ser observado que "[...] foi com a República Francesa pós-revolucionária que se acelerou a disposição de integrar os vários sistemas legais sob a base da igualdade de todos perante uma legislação comum" (WOLKMER, 2003, p. 4). No estado, portanto, residia a legitimidade única de dizer a regra jurídica.

Ainda que a colonização inglesa, seguindo o modelo de administração indireta, aceitasse com maior facilidade os costumes jurídicos locais, a França, com sua administração mais direta, pretendia assimilar - inclusive juridicamente - os povos nativos (BÔAS FILHO, 2007, p. 338). Tanto uma quanto outra, entretanto, necessitavam conhecer os povos colonizados para melhor exercer seu poder. Para isso, o orientalismo serviu com perfeição: seu conjunto de textos e práticas sustentou o imaginário sobre populações degradadas e, portanto, merecedoras da disciplina jurídica - 
em maior ou menor grau - que somente os sistemas jurídicos europeus poderiam garantir.

A noção de que o direito seria fundamentado em um " [...] conjunto de normas religiosas, jurídicas e sociais diretamente baseadas na doutrina canônica [...]" islâmica, como a sharia, era impensável (LOSANO, 2007, p. 402). O Alcorão, obra profética e religiosa fundamental, possui apenas um décimo de seus versículos destinados a regras de direito, sendo mais voltado para indicar os passos de uma vida correta (WOLKMER, 2013, p. 325). Devido a isso, a autoridade ocidental laica, guardiã da soberania e da liberdade, fazia-se sentir no Oriente, delimitando a marca divisória entre o direito "legítimo" e seus "outros": naturalizou-se a percepção de que o direito islâmico não passava de um apanhado de livros religiosos e costumes nativos.

$\mathrm{Na}$ esteira desse pensamento, a contemplação de $A$ Liberdade Guiando o Povo (DELACROIX, 1830) traz um sentimento de que, afinal, a verdade e a segurança triunfarão, redimindo as eventuais baixas de homens e mulheres durante o processo. É uma sensação bem diversa daquela que se experimenta a respeito de Fanáticos de Tanger (DELACROIX, 1837).

Nela, em um espaço bem diferente da pintura anterior, vê-se uma cidade oriental, com suas edificações brancas e tapetes coloridos. Um grupo de pessoas é representado: homens morenos, com cabelos e barbas escuras, trajando roupas árabes em tons de amarelo, vermelho e terracota, tomam a rua, em uma manifestação de violência e ferocidade. Ao centro, uma figura com camisa branca e braços levantados, em descontrole e, mais à direita, um homem sério montado a cavalo, portanto uma bandeira verde. Ao lado esquerdo, uma criança em fuga; no lado oposto, um homem protege outras duas crianças. A volta, pessoas em pé, assistindo a manifestação.

A cena diz respeito a um grupo de manifestantes religiosos - dervixes - em um ato público de frenesi. Aqui a cultura muçulmana é apresentada como selvagem, bizarra e perigosa: 
As imagens de Delacroix são na verdade não representações objetivas mas ao contrário narrativas informadas e controladas pelas preconcepções e preconceitos ocidentais. [...] Enquanto em Liberdade guiando o povo, a bandeira era uma manifestação unificadora de ideais civis carregada pela própria Liberdade, a bandeira verde é portada por um Emhaden, um líder religioso, que também retém os dervixes em correntes e cordas 3 . (HARTMANN, 2002, p. 7-8, grifos no original).

É interessante que Delacroix não tenha pintado esta obra durante sua viajem ao Marrocos, mas somente "[...] após o seu retorno à Europa, pois, assim, estaria livre para pintar apenas a emoção e não os detalhes que se postavam à sua frente" (BOTTON, BOTTON, 2012, p. 95). Uma vez que desconsiderava dados empíricos, sua narrativa não procurava a precisão, mas sim caracterizar a "estranheza" oriental e capturá-la à perspectiva europeia (SAID, 2012, p. 113).

Observando a cultura ocidental em fins do século XIX, percebe-se um reservatório de construções identitárias sobre esses estranhos seres, não ocidentais: raças inferiores, imorais, lerdos, gananciosos; detentores de uma essência imutável e necessitados, portanto, do severo jugo europeu. De maneira generalizada, tais perspectivas podem ser encontradas em peças de publicidade, cartões postais, em artefatos tão diferentes quanto jogos de tabuleiro e partituras musicais, aceitas pelas sociedades oitocentistas (SAID, 2011, p. 244-245).

Nesses tipos de representações, os povos orientais eram entidades essencializadas, demônios estrangeiros, terroristas, violentos e antidemocráticos. Uma perspectiva imperialista apressada pode levar à compreensão de que a ideia de liberdade é exclusivamente ocidental e de que:

[...] a tradição europeia é a única e inerentemente democrática, enquanto se pretende que os "outros" não europeus são natural e ine-

\footnotetext{
${ }^{3}$ Do original: Delacroix' images are in fact not objective depictions but instead shaped narratives informed and controlled by Western preconceptions and prejudices. [...] Where in Liberty Leading the People, the flag was a unifying manifestation of civic ideals carried by Liberty herself, the green banner here is held by an Emhaden, a religious leader, who also restrains the dervishes through chains or ropes.
} 
rentemente autoritários, negando ao mundo não ocidental discursos democráticos e formas de democracia institucional (que, por certo, são diferentes da democracia liberal ocidental), e como resultado, terminam apoiando formas políticas autoritárias ${ }^{4}$. (GROSFOGEL, 2011, p. 345)

Dessa forma, as lutas contra a colonização europeia eram traduzidas pelo discurso orientalista como uma incapacidade de compreensão de institutos jurídicos como liberdade e soberania, desconsiderando as resistências históricas ao domínio europeu que tais povos realizaram. Tendo como pressuposto a divisão binária das categorias "oriental" e "ocidental", a libertação e o autogoverno tinham menos importância e eram menos saudáveis aos personagens de Fanáticos de Tanger do que para os combatentes franceses em A Liberdade Guiando o Povo. Quando, mais tarde, os não ocidentais reivindicaram o fim do colonialismo, o cânone orientalista justificou tais revoltas como derivadas da influência que o conceito de liberdade ocidental exercia sobre o Oriente (SAID, 2012, p. 159; SAID, 2011, p. 314 e 402). A perspectiva saidiana nunca esteve tão atual:

Ser não ocidental (os rótulos reificantes são, em si mesmos, sintomáticos), portanto, é ser ontologicamente desafortunado em quase todos os aspectos, ser um fanático ou, na melhor das hipóteses um seguidor, um consumidor preguiçoso que pode usar o telefone, mas nunca seria capaz de inventá-lo. (SAID, 2011, p. 463)

\footnotetext{
${ }^{4}$ Do original: [...] la tradición europea es la única natural e inherentemente democrática, mientras se pretende que los "otros" no europeos son natural e inherentemente autoritarios, negándole al mundo no occidental discursos democráticos y formas de democracia institucional (que, por supuesto, son distintos de la democracia liberal occidental), y como resultado, terminan apoyando formas políticas autoritárias.
} 


\section{Espaço Privado: resistências e conformidades femininas}

\subsection{Condessa de Haussonville e a Teia Obrigacional do Casamento}

Já foi dito que toda a exclusão pressupõe alguma inclusão. A contrapartida da barbárie oriental era a civilidade europeia. Os ocidentais, assim, deviam seguir certas regras de conduta: ações, palavras, gestos, pensamentos, sentimentos que poderiam ou não realizar (SAID, 2012, p. 308). Às mulheres, artes de conversação, recato e modéstia. Aos homens, o mundo a ser conquistado. É interessante como, acima, a liberdade tenha sido prefigurada em uma imagem feminina: várias representações da República francesa a traduziam em uma jovem mulher, familiar e afetuosa (HUNT, 1991, p. 31). Era necessário que a jovem República fosse um espaço de abrigo contra a tirania e os maus-tratos - a expressão da feminilidade atenuava a violência intrínseca de uma revolução armada.

Recato, afetuosidade, local de abrigo: tais características eram consideradas próprias do sexo feminino. A subserviência era a contrapartida ao resguardo de sua fragilidade. O Code Napoléon foi bem explícito em seu art. 213: "o marido deve proteção à sua mulher e a mulher, obediência ao marido", ao ponto de a esposa ser impossibilitada de exercer tutela ou de concorrer em igualdade na herança, por exemplo, devido à sua incapacidade civil (PERROT, 1991, p. 121-122). Seu espaço era o privado, ainda que este não lhe pertencesse integralmente - o dinheiro e a palavra final eram detidos por seu marido, ou seu pai, se ainda solteira. Casada, não poderia firmar contratos nem utilizar seu salário; aliás, para exercer uma profissão, necessitava do aval do consorte, como em tudo o mais. Assim é que:

Nos meados do século XIX, na imaginação inglesa, a casa realmente era o local das doçuras e delícias, mas percebida de formas diferentes pelos homens e pelas mulheres. Os homens podiam mesclar as preocupações, temores e profundas satisfações da vida pública aos encantos recônditos do lar. Para as mulheres, raramente existia essa dualidade: possuíam apenas e exclusivamente o lar, quadro "natural" de sua feminilidade. (HALL, 1991, p. 87) 
O conservadorismo privado em meio ao furor público revolucionário é uma combinação que não se restringia a questões familiares. Também o meio artístico espelhou tal ambiguidade. O neoclassicismo era uma escola oitocentista influenciada pelo iluminismo e se caracterizava pelo resgate de antigas tradições clássicas gregas e romanas, pela manutenção de regras acadêmicas e dos estilos de grandes mestres do passado. Ao mesmo tempo, suas temáticas eram atuais e políticas, representando cenas e heróis da revolução francesa, sempre pondo em relevo sentimentos que considerava universais, como o patriotismo e a coragem (BELL, 2008, p. 312; NATIONAL GALLERY OF ART, 2015). Se as cenas históricas são grandiosas, os retratos trazem um ideal de beleza clássico, como o que se verifica na obra de Ingres.

Jean-Auguste Dominique Ingres, nascido em 1780 e falecido em 1877, lutava contra o romantismo que tomou conta da pintura francesa, representado, por exemplo, por Delacroix. Seus icônicos quadros de modelos bem vestidos, suas fantasias de concubinas orientais ocuparam um lugar de destaque na sociedade francesa da época:

A clientela que ele escolhera, suas referências clássicas e o controle linear de seu desenho conferiam-lhe um certo espaço na política da arte francesa. Até sua morte, em 1877, esse mestre do neoclassicismo revisado se tornou o epítome dos valores conservadores, apesar da estranha intensidade instintiva de suas pinturas efetivas. (BELL, 2008, p. 312)

Escolheu-se dois trabalhos desse pintor. O primeiro é o retrato da Condessa de Haussonville (INGRES, 1845). Nele, se vê uma jovem mulher com vestido de seda azul claro, cabelo arrumado com fita vermelha, retratada em frente a um espelho, sobre um aparador revestido de veludo em uma cor mais escura de azul. A vestimenta, adornada com rendas, os objetos dispostos sobre o aparador - incluindo um vaso oriental, à esquerda -, são indicadores de sua classe alta. A minúcia e o detalhismo utilizados por Ingres na elaboração do quadro explicam os três anos que ele demorou para completá-lo. Essa é uma representação clássica na pintura 
europeia do oitocentos: mulher pensativa, segurando o queixo, em atitude casta (ROUSSEL, 1985).

A exigência do decoro feminino ocidental era fundamental. A Europa oitocentista e burguesa cercava o casamento em uma teia obrigacional, em dimensões jurídicas e morais. Para a mulher, especialmente a de classe alta, esse era o objetivo maior: casar. Daí decorriam outros: cuidar de seu marido e filhos, frequentar os salões de casas de famílias amigas e conhecidas, recepcionar em sua própria casa, preocupar-se com a moda e com o corpo. Enfim, na maioria dos casos, tornar-se "insígnia do homem" (CORBIN, 1991, p. 449).

Apesar disso, e a despeito do que se pode pensar, em um rápido olhar, da modelo na pintura de Ingres, ela era Louise de Haussonville (1818-1882). Ainda que jovem e de elevada posição social, foi uma escritora liberal, reconhecida em sua época. Escolha curiosa, em um momento histórico como aquele. Eis uma das dificuldades da generalização: há sempre resistências, conformidades, ambiguidades.

A severa mas inteligente mulher publicou cinco livros incluindo uma crônica de dois volumes sobre Lord Byron e uma bibliografia não publicada. [...] Ingres a escolheu para ser uma jovem matrona que não se conformou em assumir a natureza frívola da classe governante. $\mathrm{O}$ retrato foi extremamente bem-sucedido, tanto em sua execução precisa da Condessa e de sua personalidade quanto em relação à família Haussonville e em última análise à sociedade parisiense como um todo 5 . (WERLY, 2011, p. 159-160)

Por outro lado, a divisão dos papéis masculino e feminino era uma força social. E o sexo era objeto de normalizações que o legitimavam no leito conjugal, tornando-o inapropriado ou mesmo anormal em qualquer

5 Do original: The harsh yet intelligent woman went on to publish five books including a two-volume chronicle of the life of Lord Byron and an unpublished autobiography. [...] Ingres found her to be a modest young matron who did not conform to the assumed frivolous nature of the ruling class. The portrait was extremely successful, both in its precise execution of the Comtesse and her personality and with the Haussonville family and ultimately Parisian society as a whole. 
outro lugar. Mais uma vez, o que era banido dos domínios do "eu", era enviado para o território do "outro".

\subsection{A Grande Odalisca e a Equivocada Compreensão da Cultura e do Direito Orientais}

O exotismo e a lassidão moral desses "outros" e dessas "outras" orientais podem ser observados na representação realizada na pintura A Grande Odalisca (INGRES, 1814): cortinas de seda azul ao fundo, incensário à direita da tela e uma mulher nua - e com traços ocidentais reclinada sobre almofadas, usando um turbante e segurando um leque de penas de pavão.

Esta mulher deitada sobre um divã oferece sua nudez e tem seu rosto virado para nós. O título da obra, significando "mulher de harém", assim como os acessórios orientais que a cercam sugerem o Oriente sensual. Mas essa mulher é também discreta pois ela apenas mostra as costas e uma parte de um seio. O tema do nudismo, importante no Ocidente, está sobretudo ligado à mitologia depois da Renascença, mas Ingres o transpõe aqui para outro lugar geográfico ${ }^{6}$. (LOUVRE, 2015)

Tal narrativa pictórica possui um discurso que caracteriza o Oriente com um vocabulário próprio, figuras representativas que, na verdade, mais se aproximam de personagens de teatro (SAID, 2012, p. 112-113). Essa teatralidade talvez se deva ao fato de que Ingres nunca tenha viajado ao Oriente, inspirando-se em relatos de viajantes e outras imagens, expostas em livros e diários (FARTHING, 2011, p. 408) - daí os traços ocidentais da modelo e a ausência de seu nome no título da obra. Na verdade, nenhum nome lhe cabia, sendo ela fruto da fantasia orientalista de seu criador, acrescida com tintas de literatura exótica.

\footnotetext{
${ }^{6}$ Do original: Cette femme allongée sur un divan est offerte par sa nudité et son visage tourné vers nous. Le titre de l'oeuvre, signifiant "femme de harem", ainsi que les accessoires orientaux qui l'entourent suggèrent l'Orient sensuel. Mais cette femme est aussi discrète parce qu'elle ne montre que son dos et une partie d'un sein. Le thème du nu, majeur en Occident, était surtout lié à la mythologie depuis la Renaissance, mais Ingres le transpose ici dans un ailleurs géographique.
} 
Esses escritos retratavam "[...] um lugar onde se poderia procurar a experiência sexual que não existia na Europa” (SAID, 2012, p. 263). Um espaço extravagante e permissivo, que possibilitava aos ocidentais que para lá se deslocassem uma vida com menores restrições do que a europeia, podendo fazer inúmeras atividades que não lhes eram permitidas em seus países de origem. A viagem ao Oriente, assim, também exercia o papel de iniciação sexual no imaginário de muitos jovens abastados (CORBIN, 1991, p. 467).

Ingres percorreu um caminho que tantos outros artistas trilharam: da literatura orientalista à fantasia, desta, à representação de uma cultura excêntrica que lhe era árdua a compreender. Daí decorre o hábito da arte europeia, aproximadamente na metade do século XIX, retratar a mulher oriental como dançarina, escrava, serviçal, concubina ou pertencente à luxúria de algum harém. Diversas pinturas a inseria em espaços onde "[...] a sensualidade e a crueldade surgem inevitavelmente associadas" (SAID, 2011, p. 202). É de se notar a data da finalização do quadro $A$ Grande Odalisca - 1814. A fantasia de domínio do "eu" ocidental sobre essa "outra" oriental possuía reflexos concretos: um ano após, o Ocidente já detinha domínio sobre $35 \%$ dos territórios do mundo (SAID, 2012, p. 74).

Mais uma vez, cabe lembrar a materialidade dessas representações, que se refletia na legitimação de ações tanto de mulheres europeias quanto orientais. Nas palavras de Santiago Castro-Gómez, comentando a obra de Said:

As representações, as "concepções do mundo" e a formação da subjetividade no interior dessas representações foram elementos fundamentais para o estabelecimento do domínio colonial do ocidente. Sem a construção de um imaginário de "oriente" e "ocidente", não como lugares geográficos mas como formas de vida e pensamento capazes de gerar subjetividades concretas, qualquer explicação (econômica ou sociológica) do colonialismo resultaria incompleta. [...] o orientalismo não é somente um assunto de consciência (falsa ou verdadeira) mas a vivência de uma materialidade objetiva? (CASTRO-GÓMEZ, 2005, p. 22, grifo no original)

${ }^{7}$ Do original: Las representaciones, las "concepciones del mundo" y la formación de la subjetividad al interior de esas representaciones fueron elementos fundamentales para el 
E, no entanto, esse harém tão cobiçado pelos jovens europeus, constituía-se em um espaço reservado à vida familiar, local de convivência entre parentes e criados, onde as mulheres poderiam ficar à vontade (DIB, 2011, p. 149). Também ele estava normatizado, uma vez que “[...] o direito islâmico dirige-se não ao indivíduo, mas à família [...]”, incluindo a regulação do matrimônio, poligamia, herança e filiação (LOSANO, 2007, p. 413).

Soma-se o significado da palavra "odalisca" - mal interpretado por Ingres. Elas eram criadas da casa, escravas, espólios de guerras ou compradas no mercado, ainda muito jovens. Devido a isso, não era possível estipular quais habilidades iriam desenvolver, sendo, portanto, educadas para diversas tarefas, incluindo a leitura do Alcorão, tecelagem, poesia e dança. Uma odalisca apenas teria outro tipo de vida caso se destacasse entre as demais, tornando-se concubina do sultão, uma posição hierarquicamente superior (DIB, 2011, p. 149-150).

Observando o discurso orientalista perfilado na obra em estudo (registrado, dentre outras obras, também no erotismo do Banho Turco, 1862 e na Odalisca com um Escravo, 1842, ambas de Ingres, e nas obras de Delacroix, Odalisca Reclinada sobre um Divã, 1828 e A Morte de Sadanapalos, 1827, para os quais indica-se a observação pelos leitores), tem-se a impressão de que a mulher representada é, em primeiro lugar, acessível a qualquer homem que viajasse ao Oriente. Em segundo lugar, ela nada mais seria do que um objeto de luxúria do prazer masculino.

As pinturas orientalistas, as quais foram largamente baseadas na imaginação, exerceram um importante papel em retratar a imagem da mulher árabe como uma figura sexual. Nessas pinturas, a mulher

establecimiento del dominio colonial de occidente. Sin la construcción de un imaginario de "oriente" y "occidente", no como lugares geográficos sino como formas de vida y pensamiento capaces de generar subjetividades concretas, cualquier explicación (económica o sociológica) del colonialismo resultaría incompleta. [...] el orientalismo no es sólo un asunto de "consciencia" (falsa o verdadera) sino la vivencia de una materialidad objetiva. 
árabe está dançando, tomando conta de si mesma, ou sentada fazendo nada em seu próprio espaço feminino ${ }^{8}$. (ABURWEIN, 2014)

Essa percepção desconsidera o substrato cultural e moral do espaço representado. Tais homens ocidentais não seriam admitidos nesses lugares pelo simples fato de que não pertenciam àquela família. Mais importante, em nosso ver, são as relações de poder dentro do harém. Ser odalisca, concubina e mesmo, afortunadamente, mãe de um dos filhos do sultão, se configurava em uma carreira que muitas daquelas mulheres se empenhavam em seguir.

Cabe, enfim, lembrar que, apesar do papel designado à mulher europeia do século XIX, havia aquelas que não seguiam exatamente as convenções sociais. Louise de Haussonville escreveu uma biografia de Lord Byron, ele próprio considerado um poeta maldito (SILVA, 2010, p. 8). Nesse sentido, os estudos feministas vêm questionando algumas das considerações efetuadas por Said frente à heterogeneidade de discursos no âmbito do colonialismo. Há investigações que analisam como, por meio de diários de viajem, mulheres ocidentais ora se identificavam com a opressão experimentada pelos nativos, ora compartilhavam dos discursos masculinos ocidentais de poder sobre as colônias (GARCIA-RAMÓN; MAS, 1998, p. 4-5).

É preciso recordar: a mulher europeia estava destinada a um papel público e jurídico periférico, seu lugar era em casa, cercada pelos afazeres domésticos, por seus filhos e marido. Ainda que, por um lado, as viagens oportunizassem maior liberdade - tanto social quanto geograficamente -, por outro, a reafirmação da superioridade europeia situava as mulheres lado a lado com os homens. Assim, entre críticas à conduta colonialista de oficiais e residentes e simpatias pela modernização trazida pelas administrações coloniais, diversas mulheres vivenciavam ambiguidades entre os poderes locais e ocidentais.

\footnotetext{
${ }^{8}$ Do original: The Orientalist paintings, which were largely based on imagination, played a big role in portraying the image of the Arab woman as a sexual figure. In those paintings, the Arab woman is dancing, taking care of her self, or sitting doing nothing in her own woman space.
} 


\section{Direito (Des)Colonial como Estratégia de Poder}

\subsection{Atuação do Direito no Jogo Orientalista de Inclusão-Exclusão}

A ambiguidade entre colaboração e resistência é, na verdade, parte do mundo subjetivo e objetivo criado pelo empreendimento colonial e patriarcal. A resistência ao colonialismo existiu desde o começo. Por sua parte, o colonizador sempre necessitou de nativos que cooperassem no combate a essa oposição - a força institucional não pode se fazer sentir em todo o lugar e com a mesma intensidade. Assim, a colaboração local para com a colonização europeia foi ativa, em muitos casos com a intenção de adotar a modernização da metrópole. Isso também ocorreu por meio da educação colonial, da leitura de obras eruditas e de romances, da sensação estética da pintura e da música, trazendo o estilo de vida europeu para a colônia (SAID, 2011, p. 404).

Percebe-se, assim, a conexão entre colonialismo (o domínio político da metrópole sobre a colônia e a exploração que aí se instala) e colonialidade (nascida com ele e construída a partir das percepções culturais, sexuais, políticas, dentre outras, do povo colonizador a respeito do colonizado). Como vem se discutindo, os nativos acabam por assumir tais representações como suas, ainda que elas os diminuam e subalterizem (GROSFOGUEL, 2010, p. 464-465). Ambas as identidades entrelaçam-se com as hierarquias daí provenientes, formando narrativas que ora se encontram, ora se distanciam, como nos exemplos das identificações das viajantes europeias com os não ocidentais e, ao mesmo tempo, com a administração colonial.

Essa foi uma via de mão dupla: como se viu, também a colônia era representada no Ocidente. A imagem de uma odalisca fazia o contraponto à de uma nobre francesa, uma vez que "[...] em contraposição à racionalidade e à sobriedade européias, extravagantes prazeres faziam parte da identidade oriental" (SAID, 2012, p. 132). A turba descontrolada correndo pelas ruas de Tanger ressaltava o heroísmo e a organização dos revolucionários franceses. A força da imagem, seu didatismo e convencimento eram expostos em salões e galerias. Objetos orientais eram para lá 
transportados, recebendo atenção de curiosos europeus. Shiv Visvanathan (2010, p. 565) faz a comparação: “[...] para a mente ocidental, o museu é uma grande instituição humanitária, que reflete a sensibilidade ocidental para com as culturas do passado. Mas para o olhar oriental, o museu é quase que a racionalização da pirataria”.

$\mathrm{O}$ direito, um artefato cultural potente, foi peça fundamental no empreendimento colonial e de seu patriarcalismo em ambos os lugares - tanto geográficos quanto representativos. Partindo do princípio de que havia "um" Islã (ao invés de diversas sociedades, cada qual com suas características específicas), o direito francês do século XIX pretendeu reformular suas bases jurídicas através de postulados próprios da Revolução Francesa: liberdade, igualdade, separação do Estado e da Religião, divisão entre direito público e privado, e assim por diante. Nessa esteira, inúmeros institutos jurídicos europeus foram adotados pelo mundo islâmico (LOSANO, 2007, p. 438).

A conquista dessa ocidentalização traria alguma dignidade a esse "outro", domesticando-o, hierarquizando comportamentos, assimilando juridicamente todo um espaço discursivo, reescrevendo-o segundo as regras legitimadoras do "eu" ocidental. Dessa forma, o regramento que ali se imbricou era laico em um mundo profundamente religioso; diferenciava o público do privado, em sistemas jurídicos que não atribuíam relevância alguma a essa estratificação (WOLKMER, 2012, p. 330-331).

A religião encontra-se no alicerce das sociedades muçulmanas: Islã é, literalmente, "total submissão a Deus" (LOSANO, 2007, p. 399). Rituais religiosos estão por toda a parte e não são compreendidos como aquela "selvageria" que a obra de Delacroix representou (exemplos presentes em O Massacre de Quios, 1824, e no já citado A Morte de Sadanapalos, 1827, os quais se indicou a observação), mas como parte essencial da vida cotidiana. Daí que a lei dirige-se não somente à organização social, mas - e principalmente - a uma dimensão mística e espiritual. Nela não há a separação ocidental entre direito e moral (AGUIAR, 2001, p. 272). Dessa forma: 
Decorrem por isso anacrônicas e eurocêntricas quaisquer tentativas comparadas de aproximação, e-ou subordinação, com as categorias étnicas latinas que historicamente informaram a lex no designativo "Direito", tais como "Direito Privado" e "Direito Público" ou superposição deste em relação àquele. O Islamismo consolidou dominações políticas em sentido inverso ao das etnias européias, nas quais se deu problemática e progressiva disjunção entre Coletividade-Estado e Religião. (CAMPOS NETO, 2006, p. 47, grifo no original)

Liberdade e privacidade, por exemplo, tão caras ao Ocidente, também possuem dimensões possíveis de serem associadas à obra orientalista de Ingres, aqui em estudo. Em primeiro lugar, porque a vida privada de uma mulher oriental é diferente da europeia. Seus sentidos religiosos, o uso do véu, a centralidade da família, os papéis sociais desempenhados, tudo faz com que o regramento jurídico europeu pretensamente universal não lhes seja aplicado com facilidade.

Em segundo lugar, porque a análise iconológica realizada demonstra aquela fissura que divide o "nós" e o "eles" do orientalismo: a privacidade da Condessa de Hassounville foi, em grande parte, resguardada pelo seu vestido de seda azul guarnecido com rendas; a mesma privacidade que foi negada a uma muçulmana sem nome, despida e que professava uma religião que estipula inclusive o uso do véu. É por isso que:

O racismo/sexismo epistêmico "ocidental", ao inferiorizar as epistemologias e cosmologias "não ocidentais" e privilegiar a epistemologia dos homens "ocidentais" como forma superior do conhecimento e como única fundação para definir os direitos humanos, a democracia, a justiça, a cidadania, etc, termina desqualificando o "não ocidental" como incapaz de produzir democracia, justiça, direitos humanos, conhecimento científico, etc. Isso se baseia na ideia essencialista de que a razão e a filosofia radicam no "Ocidente" enquanto que o pensamento não racional está radicado no "resto". (GROSFOGEL, 2010, p. 346, grifos no original)

9 Do original: El racismo/sexismo epistémico "occidental", al inferiorizar las epistemologías y cosmologías "no occidentales" y privilegiar la epistemologia de los 
Os direitos humanos, apanágio do constitucionalismo francês, possuem alicerce no individualismo burguês do Oitocentos, em que o conceito de liberdade tem como antítese a tirania. Na perspectiva muçulmana, ação tirânica é oposta à "ação justa” (LEWIS, 1996, p. 283). Justiça divina, aplicada pelos homens, e que se conquista inclusive pela guerra santa (jihad). A partir dos três significados da jihad, referidos por Mario Losano (2007, p. 426-427), percebe-se o quanto generalizações podem desfigurar uma imagem: além da conhecida "guerra contra os infiéis", ela também significa a polêmica com muçulmanos ocidentalizados e, igualmente, o esforço que cada um realiza para seguir as regras do Corão, apesar de todas as dificuldades encontradas - uma dimensão muito pessoal e pacífica, portanto.

Apesar de todos esses obstáculos, institutos do direito europeu foram adotados nos diversos países muçulmanos colonizados, levando a uma diminuição da aplicação da sharia. E, hoje, mesmo após a Segunda Guerra Mundial e os movimentos de independências nacionais, a colonialidade se mantém.

\subsection{Resistências e Estratégias Jurídico-Descoloniais}

Entretanto, conforme o desenrolar deste texto demonstra, existem inúmeras resistências em qualquer relação de poder - na verdade, o poder somente existe se tais oposições forem exercidas.

Pode-se indicar um sem número de resistências em relação ao tema aqui tratado: países islâmicos que aplicam, ao mesmo tempo, regras jurídicas muçulmanas e ocidentais; islamizações de instituições europeias; pluralismos jurídicos devido aos diversos sistemas de direito, que mesclam normas antigas e modernas. Soma-se, dentre outros tantos movimentos, discussões dentro dessas sociedades entre fundamentalistas e

hombres "occidentales" como forma superior del conocimiento y como único cimiento para definir los derechos humanos, la democracia, la justicia, la ciudadanía, etc. termina descalificando al "no Occidental" como incapaz de producir democracia, justicia, derechos humanos, conocimiento científico, etc. Esto se basa en la idea esencialista de que la razón y la filosofía radican en "Occidente" mientras que el pensamiento no racional radica en el "resto". 
secularistas e reivindicações de grupos organizados de mulheres e de cidadãos não muçulmanos (WOLKMER, 2012, p. 332-333). Tal perspectiva nos leva às palavras de Said:

Hoje em dia, ninguém é uma coisa só. Rótulos como indiano, mulher, muçulmano ou americano não passam de pontos de partida que, seguindo-se uma experiência concreta, mesmo que breve, logo ficam para trás. O imperialismo consolidou a mescla de culturas e identidades numa escala global. Mas seu pior e mais paradoxal legado foi permitir que as pessoas acreditassem que eram apenas, sobretudo, exclusivamente brancas, pretas, ocidentais ou orientais. No entanto, assim como os seres humanos fazem sua própria história, eles também fazem suas culturas e identidades étnicas. Não se pode negar a continuidade duradoura de longas tradições, de moradias constantes, idiomas nacionais e geografias culturais, mas parece não existir nenhuma razão, afora o medo e o preconceito, para continuar insistindo na separação e distinção entre eles, como se toda a existência humana se reduzisse a isso (grifos no original). (SAID, 2011, p. 510)

A mesma estratégia de poder que proporcionou anos de colonização (inclusive jurídica) europeia no Oriente pode ser utilizada como ferramenta para sua descolonização. Não para desconsiderar as inegáveis contribuições ocidentais, mas para reconhecer que, cada vez mais, nossas identidades são multifacetadas e que se enriquecem mutuamente. Daí o importante debate que proporcionam os estudos descoloniais. Para Walter Mignolo (2008, p. 10):

[...] "colonialidade" designa histórias, subjetividades, formas de vida, saberes e subjetividades colonizados, a partir das quais surgem as respostas "descoloniais". De maneira que se, por um lado, colonialidade é a face invisível da modernidade é também, por outro lado, a energia que gera a descolonialidade ${ }^{10}$.

\footnotetext{
${ }^{10}$ Do original: "colonialidad" designa historias, subjetividades, formas de vida, saberes y subjetividades colonizados, a partir de las cuales surgen las respuestas "descoloniales." De manera que si, por un lado, colonialidad es la cara invisible de modernidad es también, por otro lado, la energía que genera la descolonialidad.
} 
Isso nos leva a compreender como o direito colonial possui em si resistências, por assim dizer, descoloniais. As adaptações muçulmanas ao regramento europeu, o revivalismo árabe em tempos de nacionalismos, as diferentes formas de compreensão do que é a jihad, o pluralismo jurídico nesses espaços, dentre outras indicações, ocorreram no cerne da colônia, cujo domínio, está visto, não foi completo. E, no entanto, a colonialidade persiste em cada norma de direito que diferencia o "outro" de seu "eu" ocidental.

O combate ao vírus do orientalismo ainda presente, em especial, em políticas externas ocidentais (VISVANATHAN, 2010, p. 566), passa, por um lado, pelo respeito e compreensão de culturas tão diferentes quanto às de que aqui se tratou. Por outro, pelo reconhecimento de que o mundo muçulmano é muito mais do que por anos foi representado pelas artes, política e direito europeus. Hoje, talvez mais do que nunca, essa perspectiva descolonial é urgente. Países ocidentais e imperialistas, Estados Unidos especialmente, vêm ressaltando imagens fortemente orientalistas a fim de justificar barbáries (físicas, sociais, jurídicas) que jamais cometeriam de forma impune em relação aos seus próprios cidadãos. Na lúcida observação de nosso autor palestino:

A maioria das imagens representa fúria e desgraça de massas, ou gestos irracionais (por isso, irremediavelmente excêntricos). Espreitando por trás de todas essas imagens está a ameaça da jihad. Consequências: o medo de que os muçulmanos (ou árabes) tomem conta do mundo. [...] Com tais informações sobre o Iraque, que clemência, que humanidade, que chance há para argumentos humanitários? (SAID, 2012, p. 383; SAID, 2011, p. 455, grifo no original)

Enfim, uma das apostas deste texto é a do entrelaçamento de imagens e abstrações, propiciando uma compreensão de materialidades produzidas pelo direito, muitas vezes possibilitando comparações e análises inesperadas. Os artefatos daí provenientes - sejam pinturas ou normatizações - não são inocentes, traduzindo valores, escolhas e embates de seus produtores, sejam artistas, legisladores ou governantes. 
A associação entre direito e imagens não deixa de ser uma estratégia de resistência. As artes visuais podem traduzir narrativas de poder que, associadas a significados jurídicos, permitem visões diferenciadas de uma mesma questão. Como artefatos sociais, arte e direito são construções humanas, frutos de escolhas sobre o que é legitimado ou não, sendo testemunhos de normalizações sociais. São materialidades que, por sua vez, investem na produção de identidades, direcionam ações e são formadas por elas.

\section{Conclusão}

Tende-se a viver, cada um a seu modo, em espaços específicos, compartilhados com aqueles que fazem parte de nossa herança cultural. Construiu-se imagens e visões de mundo, identidades e materialidades, em grande parte pressupondo a diferenciação entre o "um" e o "outro". Esse é um binarismo fortemente reforçado pela perspectiva moderna, da qual somos todos tributários. O direito - como artefato social que é - traduz-se em local de embates, também lidando a sua maneira com uma organização social que constitui corpos e os classifica. Ele é perpassado por relações de poder e de saber, desenvolvendo estratégias que ora incluem, ora excluem pessoas, objetos e conhecimentos de espaços demarcados, organizando-os hierarquicamente por meio das mais diversas fontes: legislação, costumes e doutrinas jurídicos.

Ressalta-se, nessa linha de raciocínio, a existência dessas fontes de direito - e dos sistemas jurídicos que as instituem - como invenções, artefatos construídos mediante certas condições de possibilidade, nascidas em tramas históricas, políticas e econômicas. Nem o direito, nem seus sujeitos, possuem uma essência pré-definida, portanto. Daí a importância dos estudos descoloniais para a presente investigação, atentando nossos olhares jurídicos para a contingencialidade do conhecimento, da construção do direito e de sua aplicação. Por meio desses estudos, observa-se a positividade do poder - sua materialidade, sua capacidade de construir o mundo em que se vive. Da mesma forma, tornam-se perceptíveis as antigas relações entre países colonialistas e colonizados, assim como as novas configurações entre identidades centrais e outras, periféricas. 
Entre tais representações imaginárias e materiais, procura-se demonstrar a força de categorizações construídas em relações de poder entre colônias orientais e metrópoles ocidentais. O método iconológico possibilitou comparações, aproximações e distanciamentos na análise das imagens aqui descritas com as teorizações saidianas a respeito do orientalismo e de suas imbricações com a cultura europeia e muçulmana do oitocentos.

Evidenciou-se, assim, a imbricação entre direito, imagens, método documentário, iconologia e estudos descoloniais. A investigação nos permitiu observar produções de direito e de seu conhecimento, produtos de inúmeras decisões e aptos a construir nossas práticas sociais, especialmente no que tange às suas afirmações de neutralidade, ordem, segurança e igualdade, decorrentes de codificações e legislações estatais. A colonialidade de saber e de poder, daí advinda, exclui e inclui elementos, estabelece critérios e classificações, ícones e materialidades.

Considera-se as pinturas aqui trazidas como narrativas, atuando em um jogo de inclusão/exclusão que classificou pessoas e nações, domesticou regramentos jurídicos e criou cânones estéticos. Ao mesmo tempo, tornou-se campo de resistências e convencimentos em ambas as localidades geográficas, para, ao fim, sobrepor identidades que, hoje, são reconhecidamente mais complexas do que se convencionou aceitar.

A riqueza imaginativa e alegórica de Delacroix materializa a percepção orientalista que traça uma linha divisória entre Ocidente e Oriente. Nelas, a liberdade guia o povo francês, que continua sendo agente de suas próprias ações. Tal autonomia é negada aos orientais que correm, desenfreadamente, pelas ruas de Tanger, incapacitados pelos mais diversos motivos de se autogovernarem. Daí a necessidade de o direito europeu impor àquelas terras distantes o seu jugo, mais sábio e equilibrado do que simples conjuntos de regras religiosas.

Por sua vez, a disciplina e a diferenciação a que os corpos femininos foram submetidos pela cultura europeia do século XIX transparece nas posturas de Louise d'Haussonville e de sua "outra" oriental, ambas retratadas pela indiscutível técnica de Ingres. $\mathrm{O}$ recato (e as roupas) que existiam em uma, faltavam à outra. Ambas, entretanto, compartilhavam 
da percepção de que a feminilidade servia melhor em sua casa, em meio a seus familiares e sob o poder marital. Havia, inclusive, regras jurídicas que restringiam suas ações e reforçavam sua condição de subalternidade.

E, no entanto, a outra face do colonialismo transpareceu das mais diversas formas: da islamização de diversos conceitos jurídicos ocidentais à liberdade literária de Haussonville; da disciplina que possibilitava às mulheres orientais uma ascensão hierárquica em suas famílias à mescla plural de regramentos de direito antigo e moderno em sociedades não ocidentais. Tudo considerado, daí emergem lições para a construção de um direito descolonial em tempos nos quais é necessário estar atento às políticas internacionais de avanço imperial e colonial no Oriente.

\section{Referências}

ABURWEIN, Hibah. The negative image of the arab woman in the western literature. [2014]. Disponível em: $<$ http://www.efomw.eu/wpcontent/uploads/2013/01/arab-woman.pdf>. Acesso em: $1^{\circ}$ fev. 2015.

AGUIAR, Hugo Hortêncio de. Islamismo e Estado. Revista de Informação Legislativa, Brasília, n. 152, p. 269-274, out.-dez, 2001.

BELL, Julian. Uma Nova História da Arte. Tradução de Roger Maioli. São Paulo: Martins Fontes, 2008.

BÔAS FILHO, Orlando Villas. A constituição do campo de análise e pesquisa da antropologia jurídica. Prisma Jurídico, [S. l.]v. 6, p. 333349, 2007.

BOHNSACK, Ralf. A interpretação de imagens e o método documentário. Sociologias, [S.l.], ano 9, n. 18, p. 286-311, jun.dez., 2007. Disponível em: <http://seer.ufrgs.br/sociologias/article/ view/5659>. Acesso em: $1^{\circ}$ ago. 2014.

BOTTON, Fernanda Verdasca; BOTTON, Flavio Felicio. Ao queimar dos reinos: Sardanapalo no teatro e na pintura do romantismo. Itinerários, Araraquara, n. 34, p. 83-96, jan.-jun., 2012. 
CAMPOS NETO, Antonio Augusto Machado de. A châr 'ia muçulmana. Revista da Faculdade de Direito da Universidade de São Paulo, São Paulo, v. 101, p. 33-70, jul.-dez., 2006.

\section{CASTRO-GOMÉZ, Santiago. La poscolonialidad explicada a los} niños. Colombia: Instituto Pensar, Universidad Javeriana, 2005.

CORBIN, Alain. O segredo do indivíduo. In: PERROT, Michelle (Org.). História da vida privada 4. Tradução de Denise Bottmann e Bernardo Joffily. São Paulo: Companhia das Letras, 1991. p. 419-501.

COSTA, Lucas Piter Alves; GOMES, Renan Araújo, MELO, Mônica Santos de Souza. Dos imaginários românticos e de sua construção sígnica em La Liberté guidant le peuple. Signótica, [S. l.], v. 26, n. 2, p. 475-494, jul.-dez., 2014.

DELACROIX, Eugenè. La liberté guidant le peuple. 1830. Musée du Louvre, Paris, France. Disponível em: <http://www.louvre.fr/en/ mediaimages/le-28-juillet-la-liberte-guidant-le-peuple-28-juillet-1830-2>. Acesso em: 4 fev. 2015.

DELACROIX, Eugenè. The fanatics of Tangier. 1837. Institute of Arts - Minneapolis, Minneapolis. USA. Disponível em: $<$ http://www. eugenedelacroix.org/>. Acesso em: 4 fev. 2015.

DELACROIX, Eugenè. Mort de Sadanapale. 1827. Musée du Louvre, Paris, France. Disponível em: <http://www.louvre.fr/en/mediaimages/ mort-de-sardanapale-1>. Acesso em: 4 fev. 2015.

DELACROIX, Eugenè. Odalisque reclining on a divan. 1828. The Fitzwilliam Museum, Cambridge, England. Disponível em: $<$ https:// www.eugenedelacroix.org/Odalisque-Reclining-On-A-Divan-1827-28. html>. Acesso em: 4 fev. 2015.

DELACROIX, Eugenè. Scène des massacres de Scio. 1824. Musée du Louvre, Paris, France. Disponível em: $<$ http://www.louvre.fr/routes/ eugene-delacroix >. Acesso em: 4 fev. 2015.

DIB, Marcia. Mulheres árabes como odaliscas: uma imagem construída pelo orientalismo através da pintura. Revista UFG, [S.l.], ano XII, n. 11, p. 145-150, dez. 2011. 
FARTHING, Stephen. 1001 Paintings you must see before you die. London: Quintessessence, 2011.

FERRO, Marc. Historia das Colonizações: das conquistas às Independências. Séculos XIII a XX. São Paulo: Companhia das Letras, 1996.

FOURCADE, Marie. Os britânicos na Índia (1858-1947) ou o reinado do "cinicamente correto". In: FERRO, Marc (Org.). O livro negro do colonialismo. Tradução de Joana Angélica D’Ávila Melo. Rio de Janeiro: Ediouro, 2004. p. 345-398.

GARCIA-RAMON, Maria Dolors; MAS, Abel Albet. Los relatos de mujeres viajeras ¿Una mirada crítica sobre el colonialismo? Isabelle Eberhardt (1877-1904). FINISTERRA, Revista Portuguesa de Geografia, [S. l.], v. 33, n. 65, p. 1-10, 1998.

GROSFOGUEL, Ramón. Racismo epistémico, islamofobia epistémica y ciencias sociales coloniales. Tabula Rasa, Bogatá, n. 14, p. 341-355, enero-junio, 2011.

HALL, Catherine. Sweet Home. In: PERROT, Michelle (Org.). História da vida privada 4. Tradução de Denise Bottmann e Bernardo Joffily. São Paulo: Companhia das Letras, 1991. p. 54-87.

HARTMANN, Bjoern. Delacroix at home and abroad: a comparative analysis of early french orientalism. [2002]. Disponível em: $<$ http://bjoern. org/papers/hartmann_arth284_delacroix.pdf>. Acesso em: $1^{\circ}$ fev. 2015. HOBSBAWM, Eric. A era das revoluções. 25. ed. São Paulo: Paz e Terra, 2010.

HUNT, Lynn. Revolução Francesa e Vida Privada. In: PERROT, Michelle (Org.). História da vida privada 4. Tradução de Denise Bottmann e Bernardo Joffily. São Paulo: Companhia das Letras, 1991. p. 22-51.

INGRES, Jean-Auguste Dominique. Comtesse d'Haussonville. 1845. The Frick Collection, New York City, USA. Disponível em: $<$ http:// collections.frick.org/media/view/Objects/105/984?t:state:flow $=3 \mathrm{~d} 5$ 5e600-cacd-4c3a-affb-6bc943aa1034>. Acesso em: 4 fev. 2015. 
INGRES, Jean-Auguste Dominique. La Grande odalisque. 1814. Musée du Louvre, Paris, France. Disponível em: < http://www.louvre.fr/en/ oeuvre-notices/une-odalisque>. Acesso em: 4 fev. 2015.

INGRES, Jean-Auguste Dominique. L'Odalisque à l'esclave. 1842. Musée du Louvre, Paris, France. Disponível em: <http:/www.louvre.fr/ en/oeuvre-notices/odalisque-and-slave >. Acesso em: 4 fev. 2015.

INGRES, Jean-Auguste Dominique. Le Bain turc. 1862. Musée du Louvre, Paris, France. Disponível em: < http://www.louvre.fr/en/ mediaimages/le-bain-turc-0>. Acesso em: 4 fev. 2015.

JOLY, Martine. Introdução à análise da imagem. 14. ed. Campinas: Papirus, 2012.

KNAUSS, Paulo. O desafio de fazer história com imagens: arte e cultura visual. ArtCultura, Uberlândia, v. 8, n. 12, p. 97-115, jan.-jun., 2006.

LEWIS, Bernard. O Oriente Médio: do advento do cristianismo aos dias de hoje. Tradução de Ruy Jungmann. Rio de Janeiro: Jorge Zahar, 2006.

LOSANO, Mario G. Os grandes sistemas jurídicos. Tradução de Marcela Varejão. São Paulo: Martins Fontes, 2007.

LOUVRE. Une odalisque. [2015]. Disponível em: <http://www.louvre. fr/oeuvre-notices/une-odalisque >. Acesso em: 5 fev. 2015.

MAESTRO, Juan Ignacio Castien. Edward Said y el Orientalismo: esencialismo versus historicismo. Papeles Ocasionales, Madrid, p. 4-20, 2013.

MERLE, Marcel. O anticolonialismo. In: FERRO, Marc (Org.). O livro negro do colonialismo. Tradução de Joana Angélica D'Ávila Melo. Rio de Janeiro: Ediouro, 2004. p. 708-747.

MIGNOLO, Walter. La opción descolonial. Letral, [S.l.], n. 1, p. 4-22, 2008 .

NATIONAL GALLERY OF ART. 18th- and 19th-Century France Neoclassicism. [2015]. Disponível em: <http://www.nga.gov/content/ ngaweb/features/slideshows/18th-and-19th-century-france-neoclassicism. html\#>. Acesso em: 5 fev. 2015. 
PANIKKAR, K. M. A dominação ocidental na Ásia. São Paulo: Paz e Terra, 1977.

PERROT, Michelle. Figuras e Papéis. In: PERROT, Michelle (Org.). História da vida privada 4. Tradução de Denise Bottmann e Bernardo Joffily. São Paulo: Companhia das Letras, 1991. p. 121-185.

ROULAND, Norbert. Nos confins do direito. São Paulo: Martins Fontes, 2003.

ROUSSEL, John. Art view; Ingres's portrait of a lady is the mirror of an age. The New York Times, 24 de novembro de 1985. Disponível em: $<$ http://www.nytimes.com/1985/11/24/arts/art-view-ingres-s-portrait-ofa-lady-is-the-mirror-of-an-age.html>. Acesso em: $1^{\mathrm{o}}$ fev. 2015.

SAID, Edward W. Cultura e Imperialismo. Tradução de Denise Bottmann. São Paulo: Companhia das Letras, 2011.

SAID, Edward W. Orientalismo: o Oriente como invenção do Ocidente. Tradução de Rosaura Eichenberg. São Paulo: Companhia das Letras, 2012.

SILVA, Jorge Bastos da. O Génio e o Desespero: Byron e a Violência da Visão Romântica. In: CASTANHEIRA, Maria Zulmira; ALARCÃO, Miguel. O Rebelde Aristocrata nos 200 Anos da Visita de Byron a Portugal. Porto: Faculdade de Letras da Universidade do Porto, 2010. p. 6-23.

VIEIRA, Rafaella et al. Movimentos artísticos no século XIX:

Romantismo. Contemporâneos - Revista de Artes e Humanidades, [S.l.], n. 3, p. 1-20, nov.-abr., 2009.

VISVANATHAN, Shiv. Encontros culturais e o Oriente: um estudo das políticas de conhecimento. In: SANTOS, Boaventura de Sousa; MENESES, Maria Paula (Org.). Epistemologias do Sul. São Paulo: Cortez, 2010. p. 563-583.

WERLY, Annie. Progression of the Portrait: Ingres and Comtesse d'Haussonville. ESSAI, [S.l.], v. 9, Article 43, p. 158-161, 2011. Disponível em: $<$ http://dc.cod.edu/essai/vo19/iss1/43>. Acesso em: 2 fev. 2015. 
WOLKMER, Antonio Carlos. Dimensões do direito na cultura islâmica. In: WOLKMER, Antonio Carlos (Org.). Fundamentos de História do Direito. 7. ed. Belo Horizonte: Del Rey, 2012. p. 321-339.

WOLKMER, Antonio Carlos. Pluralismo jurídico: novo marco emancipatório na historicidade latino-americana. Cadernos de Direito, [S.l.], v. 2, n. 4, p. 1-10, 2003.

Antonio Carlos Wolkmer é professor dos Programas de Mestrado da UNILASALLE-RS, da UNESC-SC e Titular Aposentado da UFSC. Doutor em Direito. Professor Visitante em diversas universidades do Brasil e do exterior: Argentina, Chile, Equador, Colômbia, Costa Rica, México, Espanha e Itália. Pesquisador nível 1-A (CNPQ) e consultor ad hoc da CAPES. Membro do GT CLACSO (Argentina/Equador): "Pensamiento Juridico Critico" e da Associação Argentina de Sociologia Jurídica. É investigador nivel 1-A do CNPq e consultor ad hoc da CAPES. Member International Political Science Association (IPSACanada), do Instituto Internacional de Derecho y Sociedad - IIDS (Lima, Perú), e do Research Committee on Sociology of Law (RCSL).

E-mail: acwolkmer@gmail.com

Endereço profissional: Centro Universitário La Salle, Pós Graduação. Av. Victor Barreto, 2288, Centro, Canoas, RS. CEP: 920-10000.

Ana Clara Correa Henning é graduada em Direito (UFPel). Especialista em Direito (UNISINOS). Mestre em Educação (UFPel). Mestre em Direito (PUCRS). Doutora em Direito (UFSC). Professora Adjunta da Faculdade de Direito da UFPEL. Coordenadora do Grupo de Estudos Inventar: Arte e Construção do Conhecimento Jurídico (UFPel). Pesquisadora do Grupo de Pesquisa em Antropologia Jurídica (GPAJU) da UFSC.

E-mail: anaclaracorreahenning@gmail.com

Endereço profissional: Faculdade de Direito UFPel. Praça Conselheiro Maciel, s/n, Pelotas, RS. CEP: 96010-030. 
